\title{
MECHANICAL PROPERTIES OF THIN GDP SHELLS USED AS CRYOGENIC DIRECT DRIVE TARGETS AT OMEGA
}

\author{
by \\ A. NIKROO, D. CZECHOWICZ, K.C. CHEN, \\ M. DICKEN, C. MORRIS, R. ANDREWS, \\ A.L. GREENWOOD, and E. CASTILLO
}




\section{DISCLAIMER}

This report was prepared as an account of work sponsored by an agency of the United States Government. Neither the United States Government nor any agency thereof, nor any of their employees, makes any warranty, express or implied, or assumes any legal liability or responsibility for the accuracy, completeness, or usefulness of any information, apparatus, product, or process disclosed, or represents that its use would not infringe privately owned rights. Reference herein to any specific commercial product, process, or service by trade name, trademark, manufacturer, or otherwise, does not necessarily constitute or imply its endorsement, recommendation, or favoring by the United States Government or any agency thereof. The views and opinions of authors expressed herein do not necessarily state or reflect those of the United States Government or any agency thereof. 


\title{
MECHANICAL PROPERTIES OF THIN GDP SHELLS USED AS CRYOGENIC DIRECT DRIVE TARGETS AT OMEGA
}

\author{
by \\ A. NIKROO, D. CZECHOWICZ, K.C. CHEN, \\ M. DICKEN, $\uparrow$ C. MORRIS, $\neq R$. ANDREWS, \\ A.L. GREENWOOD, and E. CASTILLO \\ tUniversity of California, San Diego \\ ‡Cornell University
}

This is a preprint of a paper presented at the 15th Target Fabricartion Specialists Meeting, Gleneden Beach, Oregon, June 1-5, 2003 and to be published in Fusion Science and Technology.

\author{
Work supported by \\ the U.S. Department of Energy \\ under Contract No. DE-AC03-01SF22260
}

GENERAL ATOMICS PROJECT 30095

SEPTEMBER 2003 


\title{
MECHANICAL PROPERTIES OF THIN GDP SHELLS USED AS CRYOGENIC DIRECT DRIVE TARGETS AT OMEGA
}

\author{
A. Nikroo, D.G. Czechowicz, K.C. Chen, M. Dicken, ${ }^{\dagger}$ C. Morris ${ }^{\ddagger}$ R. Andrews, A. Greenwood, and E. Castillo \\ General Atomics, P.O. Box 85608, San Diego, California 92186-5608 \\ email: nikroo@gat.com \\ ${ }^{\dagger}$ University of California, San Diego, La Jolla, California 92093-0319 \\ ¥Cornell University, Ithaca, New York 14853-2801
}

Thin glow discharge polymer (GDP) shells are currently used as the targets for cryogenic direct drive laser fusion experiments. These shells need to be filled with nearly $1000 \mathrm{~atm}$ of $\mathrm{D}_{2}$ and cooled to cryogenic temperatures without failing due to buckling and bursting pressures they experience in this process. Therefore, the mechanical and permeation properties of these shells are of utmost importance in successful and rapid filling with $D_{2}$. In this paper, we present an overview of buckle and burst pressures of several different types of GDP shells. These include those made using traditional GDP deposition parameters ("standard GDP") using a high deposition pressure and using modified parameters ("strong GDP") of low deposition pressure that leads to more robust shells.

\section{INTRODUCTION}

Thin-walled glow discharge polymer (GDP) shells are currently used as targets for OMEGA cryogenic direct laser fusion experiments. ${ }^{1}$ These shells are filled at OMEGA Cryogenic Target Handling System with $\sim 1000$ atm of $D_{2}$ and cryogenically cooled to freeze the $\mathrm{D}_{2}$ without failing from buckling and bursting pressures during the filling and cooling processes. Knowledge of the buckling strength and permeation properties of the shells is essential for a proper filling schedule to ensure survival of shells during the high pressure fill.

We have been fabricating thin walled $\mathrm{CH}$ and $\mathrm{CD}$ shells, $\sim 900 \mu \mathrm{m}$ in diameter, for OMEGA cryogenic experiments for the past several years using the depolymerizable mandrel technique. ${ }^{2-4}$ They typically have been $\sim 3 \mu \mathrm{m}$ in wall thickness, but shells with wall thicknesses of $1-5 \mu \mathrm{m}$ may be needed in the near future. These shells are produced in two varieties. The first type, designated as "standard" type, is produced with standard
GDP deposition parameters. The second type is made using a modified deposition condition that have resulted in shells that have superior buckle strength, hence termed "strong" GDP shells. 4 These thin-walled shells, including "standard" $\mathrm{CH}$ and "strong" $\mathrm{CH}$, and "strong" $\mathrm{CD}$, have been used at the University of Rochester's Laboratory for Laser Energetics (UR/LLE) for cryogenic experiments. While some buckle strength data was obtained for these types of shells previously, 2,3 a comprehensive set of strength data for these shells in the thickness range of interest, $\sim 1 \mu \mathrm{m}$ to $5 \mu \mathrm{m}$, had not been compiled. In particular, the influence of wall thickness (shell aspect ratio) on shell strength had been assumed to follow that of an ideal thin wall shell. We have compiled the desired data and present it in this paper. Data have been collected on the buckle and burst strengths from the delivered batches as well as on samples from quality control runs. These shells encompass the desired range of wall thickness that allows the thickness dependence of shell buckle and burst strength to be examined closely. In particular, deviations from the ideal shell behavior have been identified. Such information is important in extending the shell fabrication range to thinner shells. Also, it has direct impact on eventual shell fabrication for direct drive ignition experiments on the National Ignition Facility (NIF). The relatively large volume of data also permits us to verify the reproducibility of the process between different production batches.

\section{EXPERIMENTAL DETAILS}

Thin wall $\mathrm{CH}$ and $\mathrm{CD}$ shells of the "strong" and "standard" types were fabricated for these tests in several different batches. Data was also collected on production batches fabricated for OMEGA experiments. Due to the extreme "softness" of the "standard" CD shells they 
tended to stick to the vessels used for the pyrolysis step in fabrication and were mostly destroyed in that process. Therefore, very little data on "standard" CD shells was obtained and that data is not presented here in detail.

In general, buckle and burst tests were performed on five to ten shells from batches of each type. 3 to 4 shells were placed in cylindrical cells $(1.25 \mathrm{~mm}$ i.d. and $4 \mathrm{~mm}$ height) in a small holder with a glass viewing port under a microscope. Shells were observed in real time using a video camera. Since some of the shells bounce back after buckling, direct real-time monitoring is crucial for proper determination of the buckle strength. The pressure could be regulated between 0 and $\sim 300$ psi ( 20 atm) with 0.1 psi resolution using a Tescom programmable pressure controller. For the buckle test, the cell was instantly pressurized to the test pressure and held for $\sim 1 \mathrm{~s}$, to minimize permeation across the shell wall, and then the pressure released. Nitrogen gas was used for buckle tests due to the relatively long time constant of GDP shells ( $5 \mathrm{~min}$ for a $1 \mu \mathrm{m}$ shell) for this gas to avoid the undesired accumulation of the test gas in shells during testing. The shells were examined for survival or failure during this process. The test pressure was then increased in $\sim 0.1-$ 0.5 psi steps depending on shell wall thickness and the test repeated until all the shells had buckled. The initial pressure step used depended on shell thickness, with a larger initial step used for the thicker shells. This was done to further avoid accumulation of nitrogen in the shells during testing. It should be noted that "strong" $\mathrm{CH}$ and CD shells failed by shattering into many pieces, while the "standard" shells usually flattened and then bounced back.

For burst tests, helium was chosen as the test gas due to its low permeation time constant $(\sim 7 \mathrm{~s}$ for a $1 \mu \mathrm{m}$ shell) allowing rapid filling of shells and reducing the total test time. To avoid buckling of shells, the cell pressure was gradually raised to the test pressure and held at that pressure for longer than $3 \mathrm{~min}$ to ensure complete filling of the shells. The cell was then instantly $(<<1 \mathrm{~s})$ depressurized to $1 \mathrm{~atm}$ and shells were examined for failure. Therefore, the maximum achievable pressure difference for burst testing was $19 \mathrm{~atm}$ due to system limitations. The rapid depressurization ensured that minimal amount of helium had leaked out of the shell and that they experienced the intended burst pressure. The process was repeated, increasing the test pressure by $1 \mathrm{~atm}$ until all shells had burst.

\section{RESULTS AND DISCUSSION}

The buckle strength of an ideal thin wall shell is related to its aspect ratio (AR) by, 5

$$
\mathrm{P}_{\text {Buckle }}=\frac{8 \mathrm{E}}{\sqrt{3\left(1-v^{2}\right)}} \frac{1}{(\mathrm{AR})^{2}},
$$

Where $\mathrm{E}$ and $v$ are the Young's modulus and the Poisson's ratio of the shell materials, respectively, and $A R$ is the ratio of the shell diameter (d) to its wall thickness (w). For GDP shells the Poison's ratio is assumed to be 0.3 , a typical value for polymers. As mentioned previously, fabrication of thin "standard" CD shells proved to be difficult and many of the shells had fabrication related defects. The calculated Young's modulus based on a small sample of shells was $\sim 1.0 \mathrm{GPa}$. These shells were not further investigated.

Figure 1 compares the buckle strength of "normal" and "strong" $\mathrm{CH}$ and "strong" $\mathrm{CD}$ shells plotted as a function of the inverse of square of shell's the aspect ratio, $1 / \mathrm{AR}^{2}$. As shown in the figure, the buckle strength of the "strong" $\mathrm{CH}$ shells is substantially higher than that of the "standard" $\mathrm{CH}$ shells for each thickness. It is also higher than that of "strong CD" shells. The buckle strength data is fit to Eq. (1) and from the slope of the fit, the Young's modulus for each type of shell material can be determined. From the slope, the Young's moduli for "strong" $\mathrm{CH}$, "strong" $\mathrm{CD}$ and "standard" $\mathrm{CH}$ were calculated to be $2.8 \mathrm{GPa}, 2.4 \mathrm{GPa}$ and $1.9 \mathrm{GPa}$, respectively. While the line fits in the Fig. 1 appear to be linear, close examination of data shows there is indeed a difference in thickness dependency in "standard" and "strong" $\mathrm{CH}$ in 1 to $5 \mu \mathrm{m}$ range. Figure 2(a) shows the Young's moduli calculated from the same data using Eq. (1) for each thickness. The data shows that the calculated Young's modulus for "standard" $\mathrm{CH}$ shells show thickness dependency. If these shells behaved as ideal shells the E value should be constant. This is indeed the case for the "strong" $\mathrm{CH}$ shells within the $10 \%$ experimental error in the thickness range of interest (1$5 \mu \mathrm{m}$ ). However, for the "standard" $\mathrm{CH}$ shells the E value decreases for decreasing wall thickness $(\sim 50 \%)$ in the $1-$ $5 \mu \mathrm{m}$ thickness range. To further examine this thickness dependency of normal $\mathrm{CH}$ shells, data was also taken for much thicker batches of "standard" $\mathrm{CH}$ shells. The data demonstrated that the $E$ value appeared to rise rapidly for thicknesses below $\sim 5 \mu \mathrm{m}$ and then plateaued at about

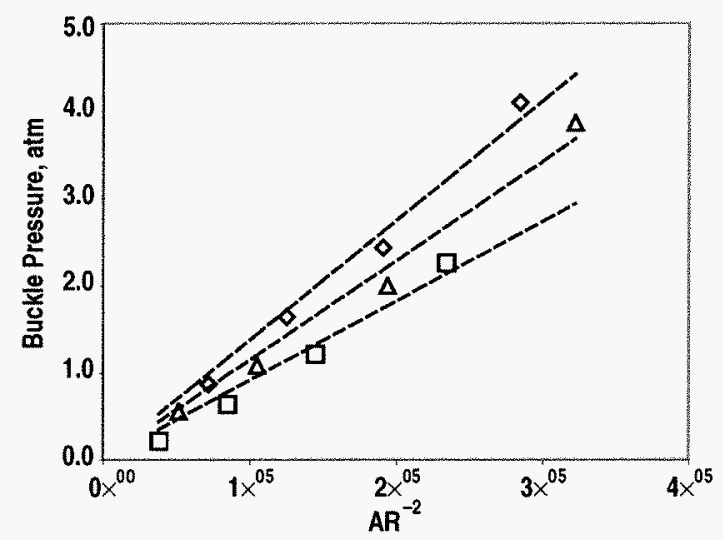

Fig. 1. Buckle pressures of "standard" (squares) and "strong" $\mathrm{CH}$ (diamonds) and "strong" CD (triangles) shells as a function of shells aspect ratio (AR). The lines are fits to data according to Eq. (1) and are used to calculate an average Young' modulus for each type. 

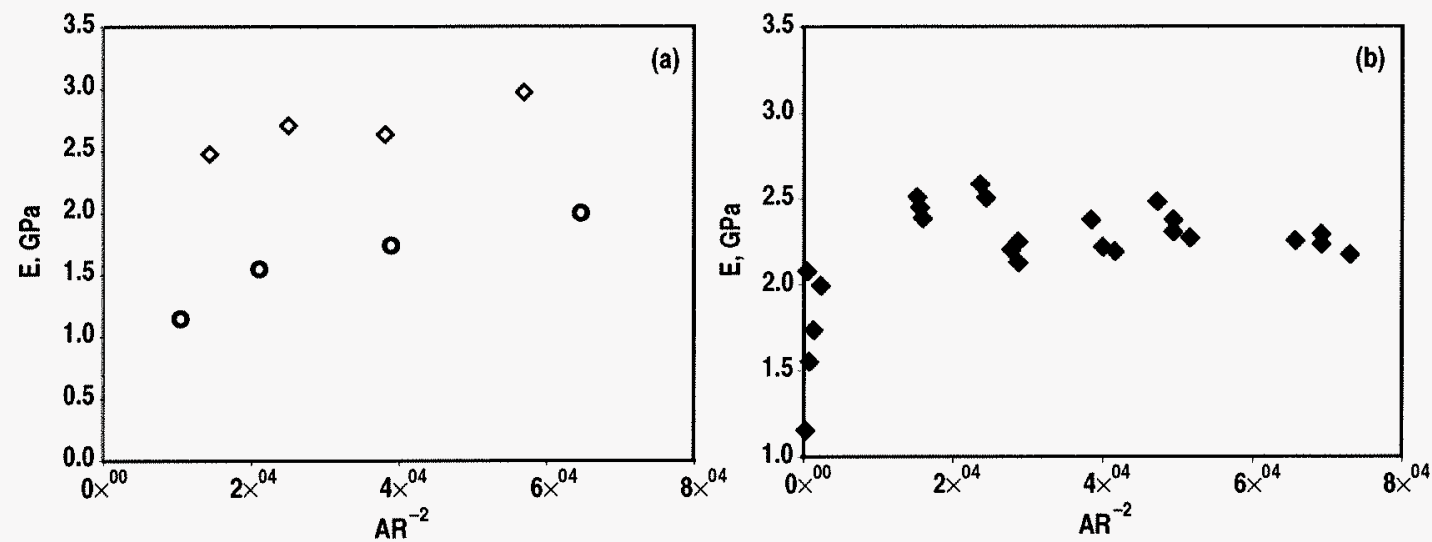

Fig. 2. (a) the calculated Young's moduli of "standard" (circles) and "strong" $\mathrm{CH}$ (diamonds) shells shows strong thickness dependency of "standard" CH shell. (b) The Young's moduli of "standard" $\mathrm{CH}$ shells with wider thickness span show a plateau at 5-6 $\mu \mathrm{m}$ thickness range.

2.3 GPa for greater thicknesses [Fig. 2(b)]. This thickness dependency trend is also somewhat present in "strong" CD shells but again not as pronounced as for "standard" CH shells (Fig. 3).

It is important to recognize that the calculated values for the Young's modulus of these shells using the Eq. (1) do not necessarily mean that this fundamental property of the shell material is changing with thickness. It simply may indicate that the thinner shells exhibit deviations from the theoretical behavior expected of "ideal" thin wall shells. This deviation may actually indicate that the thinner "standard" shells behave more like deformable viscoelastic membranes that no longer follow Eq. (1), rather than a real change in elastic modulus property. The buckling characteristics of the thinner "standard" $\mathrm{CH}$ shells is however noticeably different (they flatten and bounce back) than those of thicker "standard" $\mathrm{CH}$ shells (they shatter). While further studies are required to clarify this, the present study points out the danger in extrapolation of the Young's modulus, and hence the expected buckle strength to higher aspect ratio shells from values obtained from lower aspect ratio shells. This has a

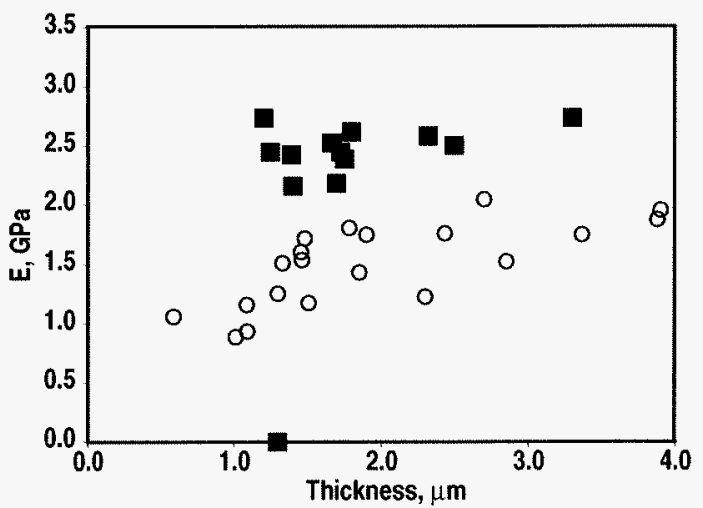

Fig. 3. The comparison of thickness dependence of elastic modulus of "strong" $\mathrm{CH}$ (closed squares) and "strong" CD shells (open circles). direct bearing on NIF scale cryogenic direct drive targets which are supposed to have much larger aspect ratios.

For burst testing the key material parameter involved is the tensile strength. The tensile strength of a thin shell is calculated from burst pressure using the following equation: ${ }^{5}$

$$
\mathrm{P}_{\text {Burst }}=\frac{4 \sigma}{\mathrm{AR}} \text {, }
$$

where $s$ is the tensile strength of the material. The burst strengths of the "strong" and "standard" $\mathrm{CH}$ and "strong" $\mathrm{CD}$ shells were also examined the $1-5 \mu \mathrm{m}$ wall thickness range (Fig. 4). Interestingly, despite the differences seen in buckle strength between the different types, all three had similar burst pressure trends. Using Eq. (2), the tensile strength is calculated to be $\sim 800 \mathrm{~atm}$ regardless of type. It should be pointed out that the tensile strength for "strong" $\mathrm{CH}$ shells was somewhat underestimated since all the thickest shells $(5 \mu \mathrm{m})$ survived at our system test pressure limit of $19 \mathrm{~atm}$.

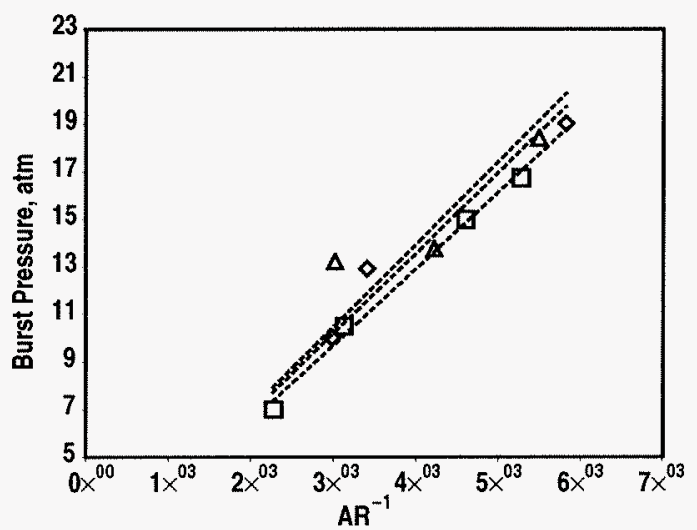

Fig. 4. The burst pressure of three different types of GDP shells, "standard" (squares) and "strong" CH (diamonds) and "strong" $\mathrm{CD}$ (triangles), as a function of shell's aspect ratio. The lines are fits to Eq. (2) and are used to calculate the tensile strength of each type. 
The understanding of the burst strength of "strong" CD shells is especially crucial since it is currently the material of choice for use for cryogenic OMEGA shots. Therefore, extensive burst pressure data was collected on "strong" CD shells to verify the ability of the shells to survive the several or more atm of burst pressure that shells may experience due to thermal non-uniformities during the cooling cycle at OMEGA. All shells tested had the typical wall thickness of 3-4 $\mathrm{m}$, or aspect ratio of 240-300 since shell diameters are $-900 \mathrm{~mm}$. They were subjected from several up to 19 atm of burst pressure. Nearly 100 shells were tested from a number of production batches. Figure 5 shows the shells consistently survived at least $10 \mathrm{~atm}$ burst pressure. The reproducibility demonstrates the consistency in the GDP shell fabrication.

\section{CONCLUSIONS}

Extensive buckle and burst tests were performed on the "strong" and "standard" CH and "strong" CD shells in the wall thickness range of $1-5 \mu \mathrm{m}$ which is of interest for cryogenic applications at OMEGA. The Young's moduli for strong $\mathrm{CH}$, strong $\mathrm{CD}$ and normal $\mathrm{CH}$ were calculated to be $2.8 \mathrm{GPa}, 2.4 \mathrm{GPa}$ and $1.9 \mathrm{GPa}$, respectively. It was found that "strong" $\mathrm{CH}$ has the highest buckle strength

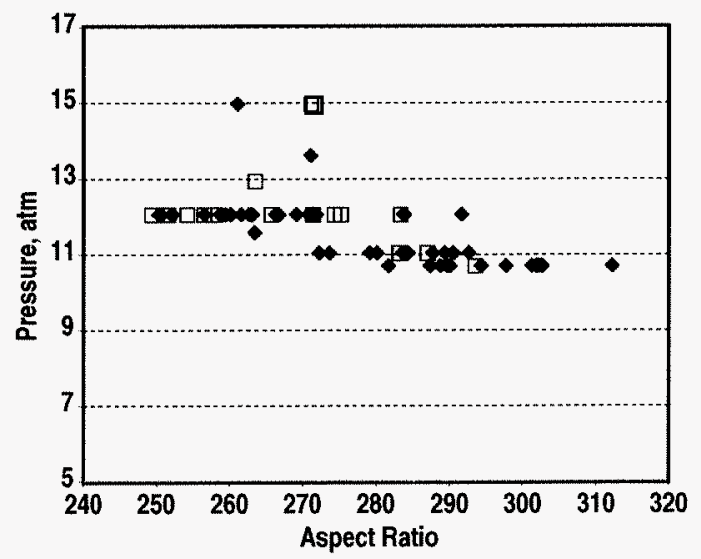

Fig. 5. Extensive burst testing on shells from various batches of "strong" CD shells shows no failure of shells at least below $10 \mathrm{~atm}$ and the consistency of the shell fabrication process. Survived (closed diamonds), failed (open square). and therefore an inferred Young's modulus value among the three types at the same thickness. "Standard" $\mathrm{CH}$ and "strong" CD exhibit deviations from the ideal shell behavior in buckling, with the deviation being stronger for "standard" CH. The burst tests show all three types of shell have similar tensile strength of $800 \mathrm{~atm}$. The burst tests on a large set of "strong" CD shells from a number of production batches showed no failure of shells at least $10 \mathrm{~atm}$ as required for survival when used at OMEGA.

\section{ACKNOWLEGMENT}

Work supported by the U.S. Department of Energy under Contract DE-AC03-01SF22266.

\section{REFERENCES}

1. C. STOECKL, C. CHIRITESCU, J.A. DELETTREZ, R. EPSTEIN, V.Y. GLEBOV, D.R. HARDING, R.L. KECK, S.J. LOUCKS, L.D. LUND, R.L. MCCRORY, P.W. MCKENTY, F.L. MARSHALL, D.D. MEYERHOFER, S.F.B. MORSE, S.P. REGAN, P.B. RADHA, S. ROBERTS, T.C. SANGSTER, W. SEKA, S. SKUPSKY, V.A. SMALYUK, C. SORCE, J.M. SOURES, R.P.J. TOWN, J.A. FRENJE, et al., "First Results from Cryogenic Target Implosions on OMEGA," Phys. of Plasmas. 9 (5 Part 2): 2195-2201, (2002).

2. S.A. LETTS, E.M. FEARON, S.R. BUCKLEY, M.D. SACULA, L.M. ALLISON, R.C. COOK, "Preparation of Hollow ICF Targets Using a Depolymerizable Mandrel," Mat. Res. Soc. Symp. Proc. 372125 (1995).

3. A. NIKROO and J.M. PONTELANDOLFO, "Fabrication of Thin Walled Glow Discharge Polymer Shells," Fusion Technology, Vol. 38, no.1, pp. 58-61 (2000).

4. A. NIKROO, D. CZECHOWICZ, E.R. CASTILLO, J.M. PONTELANDOLFO,"Recent Progress in Fabrication of High-Strength Glow Discharge Polymer Shells by Optimization of Coating Parameters," Fusion Science and Technology, Vol. 41, no. 3, pp. 214-219 (2002).

5. W.C. YOUNG, Roarke's Formulas for Stress and Strains, 6th edition, McGraw Hill, 1989. 